\title{
Analysis of Genetic Relatedness of Dieffenbachia Cultivars Using AFLP Markers
}

\author{
Jianjun Chen, ${ }^{1,2,4}$ Richard J. Henny, ${ }^{1,2}$ and David J. Norman ${ }^{1,4}$ \\ Institute of Food and Agricultural Sciences, University of Florida, 2725 Binion Road, Apopka, \\ FL 32703-8504 \\ Pachanoor S. Devanand and Chih-Cheng T. Chao ${ }^{5}$ \\ Department of Botany and Plant Sciences, University of California Riverside, Riverside, 2137 Batchelor \\ Hall, CA 92521-0124
}

\begin{abstract}
AdDitional INDEX WORDS. amplified fragment length polymorphism, Araceae, Dieffenbachia breeding, dumb cane, ornamental tropical foliage plants

Abstract. Dieffenbachia Schott is an important ornamental foliage plant genus. Atotal of 30 species has been recognized, but most cultivars come from or are related to a single species, $D$. maculata (Lodd.) G. Don. At least 11 of the cultivars are sports or somaclonal variants. As a result, the potential lack of genetic diversity in cultivated Dieffenbachia has become a concern. However, no research has been conducted to determine the genetic relatedness of the cultivars. This study analyzed the genetic similarity of 42 Dieffenbachia cultivars using amplified fragment length polymorphism (AFLP) markers. Six primer sets, selected from an initial screening of 48, generated a total of 453 scorable AFLP fragments of which $323(71 \%)$ are polymorphic. All cultivars were clearly differentiated by their AFLP fingerprints. A dendrogram was constructed using the unweighted pair-group method of arithmetic averages, and principal coordinated analysis was carried out to show multiple dimensions of the distribution of the cultivars. The $\mathbf{4 2}$ cultivars were divided into three clusters; clusters I and II comprise 18 and 23 cultivars, respectively. Jaccard's similarity coefficients for cultivars in the clusters I and II varied from 0.44 to 0.95 and 0.41 to 0.87 , respectively. These results indicate that broadening the genetic variability in the Dieffenbachia gene pool is needed, but the genetic similarity of many cultivars is not as close as previously thought. Additionally, Jaccard's similarity coefficients between most sports or somaclonal variants and their parents were 0.73 or lower, suggesting that accumulation of somatic mutations through tissue culture may play a role in the increased variation between some sports or variants and their parents.
\end{abstract}

Dieffenbachia Schott, commonly known as dumb cane, belongs to the family Araceae Juss. and comprises 30 species of broad-leaved, upright, herbaceous plants indigenous to South and Central America (Mayo et al., 1997). Flowers are unisexual, dichogamous in nature, and the chromosome number of most species is $2 n=34$ (Jones, 1957). Due to their attractive foliar variegation, tolerance to low light levels, and ease of production, dumb canes have been produced as ornamental foliage plants for interior decoration or grown as ground cover for shaded sites in tropical regions (Chen et al., 2002).

Since the first hybrid, D. x Bausei, was developed in 1870 in the garden of the Royal Horticultural Society of London at Chiswick (Birdsey, 1951), more than 100 hybrids or sports have been released (Griffith, 1998). However, there have been no institutionalized systems in conserving Dieffenbachia. Genetic resources, mainly collected and maintained by private plant collectors or some public institutions, such as botanical gardens or conservatories (Henny and Chen, 2003), could be eroded due to the expense of maintaining tender tropical plants in greenhouses.

Received for publication 18 Apr. 2003. Accepted for publication 22 Sept. 2003. Authors like to thank Agri-Starts, Inc., Apopka, Fla., Batson's Greenhouse, Inc. Mt. Dora, Fla., Twyford International, Inc., Apopka, Fla., and University of California Riverside Botanic Garden, Riverside, Calif., for providing plant materials used in this study and Kelly Everitt for critical reading of this manuscript. This research was supported in part by the Florida Agricultural Experiment Station, California Agricultural Experiment Station, and University of California Cooperative Extension.

${ }^{1}$ Mid-Florida Research and Education Center.

2Department of Environmental Horticulture.

${ }^{3}$ Department of Plant Pathology.

${ }^{4}$ Corresponding author; e-mail jjchen@mail.ifas.ufl.edu.

${ }^{5}$ Corresponding author; e-mail ctchao@ citrus.ucr.edu.
For example, there are only 20 commercially produced cultivars in Florida in 2003 compared to 30 a decade ago, and many of cultivars listed in 1993 are no longer available (FNGA, 1993, 2003). The Ornamental Plant Germplasm Center (OPGC) at Ohio State University is considering conservation of five genera from the family Araceae including Dieffenbachia at this time.

Among hybrids developed, $>90 \%$ of them were selected from crosses that had cultivars of $D$. maculata (Lodd.) G. Don (formerly $D$. picta Schott, $2 n=34$ ) as parents. Additionally, many cultivars are sports or somaclonal variants derived from cultivars related to D. maculata. Furthermore, commercial Dieffenbachia production has often used propagules derived from tissue culture. Subsequently, the potential lack of genetic diversity in cultivated Dieffenbachia has been a great concern as the genetic vulnerability to new diseases and pests may increase and genetic variability for cultivar improvement may decrease (Henny, 1977). However, no studies have been conducted to determine the genetic relatedness of Dieffenbachia cultivars.

Amplified fragment length polymorphism (AFLP) is a novel PCR-based assay for plant DNA fingerprinting that reveals significant levels of DNA polymorphism (Vos et al., 1995). The advantages of this technique include reproducibility, high levels of polymorphism detection, genome-wide distribution of markers, and no required prior knowledge of the genome being studied (Prabhu and Gresshoff, 1994). AFLP has been used to study genetic relationships of a wide range of species, including some ornamentals such as Caladium Venten. spp. (Loh et al., 1999; Loh et al., 2000), Hemerocallis L. spp. (Tomkins et al., 2001), Pelargonium peltatum (L.) L'Her. Ex Ait. (Barcaccia et al., 1999), Rosa L. (Debener et al., 2000), and Orchis simia Vill. (Qamaruz-Zaman et al., 1998). Thus, the objective of this 
study was to determine genetic relatedness of currently cultivated Dieffenbachia.

\section{Materials and Methods}

Plant materials. Forty-two Dieffenbachia cultivars, along with one cultivar each of five other ornamental foliage aroid genera [Anthurium Schott, Alocasia (Schott) G. Don, Aglaonema Schott, Philodendron Schott, and Spathiphyllum Schott] were collected and used in this study (Table 1). The collections were made from either the research greenhouses at the University of Florida's Mid-Florida Research and Education Center (MREC), ornamental foliage plant nurseries in central Florida, or University of California Riverside Botanic Garden.

FLUORESCENT-AFLP ANALYSIS. Total DNA was extracted from young leaves using the DNeasy system (Qiagen, Valencia, Calif.). After DNA quantification using a Hoefer DyNA Quant 200 (Pharmacia Biotech, Piscataway, N.J.), AFLP analysis was conducted using the GIBCO BRLAFLPSystem II (Life Technologies, Grand Island, N.Y.) and visualized with an automated sequencer (4000L; LI-COR Inc., Lincoln, Nebr.). Total DNA (125 ng) from all samples was digested with $1 \mu \mathrm{L}$ of mixture of EcoR I/Mse I (1.25 units $/ \mu \mathrm{L})$ at $37^{\circ} \mathrm{C}$ overnight, and ligated to EcoRI/Mse I adapters with $1.5 \mu \mathrm{L}(1 \mathrm{unit} / \mu \mathrm{L})$ of T4 DNA ligase at $25^{\circ} \mathrm{C}$ for at least 6 hrs. The adaptor-ligated DNA was amplified using a mixture of $2.5 \mu \mathrm{L}$ of DNA from the ligation reaction, $20 \mu \mathrm{L}$ of Preamp mix II, $2.5 \mu \mathrm{L}$ of $10 x$ PCR buffer, and $0.2 \mu \mathrm{L}$ of Taq DNA polymerase ( 5 units $/ \mu \mathrm{L})$. The preamplification reactions were performed on a MJR Cycle LR (MJ Research, Inc., Watertown, Mass.) using the following cycling parameters: 30 cycles at $94{ }^{\circ} \mathrm{C}$ for $15 \mathrm{~s}, 56{ }^{\circ} \mathrm{C}$ for $30 \mathrm{~s}+1 \mathrm{~s} /$ cycle, and $72{ }^{\circ} \mathrm{C}$ for $1 \mathrm{~min}+1 \mathrm{~s} /$ cycle, then 1 cycle at $72{ }^{\circ} \mathrm{C}$ for $3 \mathrm{~min}$. The preamplified PCR product was quantified in the fluorometer, and the amount of template for subsequent PCR was diluted to $125 \mu \mathrm{g} \cdot \mu \mathrm{L}^{-1}$. Selective amplification was performed using a reaction mix composed of $2 \mu \mathrm{L}$ of DNA from preamp, 2 $\mu \mathrm{L}$ of $M s e$ I primer $(8.3 \mu \mathrm{M}), 0.5 \mu \mathrm{L}$ of IRD700-labeled EcoR I primer $(1 \mu \mathrm{M}), 0.5 \mu \mathrm{L}$ of IRD800-labeled EcoR I primer $(1 \mu \mathrm{M})$, $1 \mu \mathrm{L}$ of $10 x$ PCR buffer, $4 \mu \mathrm{L}$ of $\mathrm{H}_{2} \mathrm{O}$, and $0.16 \mu \mathrm{L}$ of Taq DNA polymerase ( 5 units/ $\mu \mathrm{L})$

The selective amplification PCRs were performed by another touchdown program as follows: 13 cycles at $94{ }^{\circ} \mathrm{C}$ for $15 \mathrm{~s}, 65$ ${ }^{\circ} \mathrm{C}$ for $30 \mathrm{~s}-0.7{ }^{\circ} \mathrm{C} /$ cycle, and $72{ }^{\circ} \mathrm{C}$ for $1 \mathrm{~min}$, then 30 cycles at $94{ }^{\circ} \mathrm{C}$ for $15 \mathrm{~s}, 56{ }^{\circ} \mathrm{C}$ for $30 \mathrm{~s}+1 \mathrm{~s} /$ cycle, $72{ }^{\circ} \mathrm{C}$ for $1 \mathrm{~min} .+1$ s/cycle, then $72{ }^{\circ} \mathrm{C}$ for $3 \mathrm{~min}$. Both pre and selective-amplification conditions were modified according to Myburg et al. (2000). The products from the selective amplification were electropho-

Table 2. AFLP primer combinations, primer sequences, total number of bands generated by each primer set, number of polymorphic bands detected, and percentages of polymorphic bands used in the study of Dieffenbachia cultivars.

\begin{tabular}{lccc}
\hline & $\begin{array}{c}\text { Total } \\
\text { no. of } \\
\text { bands }\end{array}$ & $\begin{array}{c}\text { No. of } \\
\text { polymorphic } \\
\text { bands }\end{array}$ & $\begin{array}{c}\text { Percent of } \\
\text { polymorphic } \\
\text { bands }\end{array}$ \\
\hline Primer & 77 & 48 & 62.3 \\
IRD700 E+TC/M+CAA & 69 & 50 & 72.5 \\
IRD700 E+TC/M+CAT & 69 & 53 & 76.8 \\
IRD800 E+AA/M+CAT & 61 & 41 & 67.2 \\
IRD700 E+GG/M+CAA & 84 & 64 & 76.2 \\
IRD800 E+CC/M+CAA & 93 & 67 & 72.0 \\
Total & 453 & 323 & 71.3 \\
Average & 75.5 & 53.8 & 71.3 \\
\hline
\end{tabular}

resed on $25 \mathrm{~cm} \times 0.25 \mathrm{~mm} 8 \%$ denaturing polyacrylamide Long Ranger Gel Solution (BMA, Rockland, Maine) in 0.8x TBE buffer using a LI-COR automated sequencer 4000-L. The gel was prerun for 10 to $20 \mathrm{~min}$ at $1,500 \mathrm{~V}, 40 \mathrm{~mA}$, and $40 \mathrm{~W}$ until the gel temperature reached $50{ }^{\circ} \mathrm{C}$. The samples were denatured at $95{ }^{\circ} \mathrm{C}$ for $3 \mathrm{~min}$ and immediately placed on ice. Electrophoresis was performed at $1500 \mathrm{~V}, 50{ }^{\circ} \mathrm{C}$ for $3.5 \mathrm{~h}$ after $1.15 \mu \mathrm{L}$ samples and $1 \mu \mathrm{L}$ of a mixture of IRD700 and IRD800 size markers were loaded (Li-COR).

In total, 48AFLP primers were initially screened, from which six primer sets (IRD700 E+TC/M+CAA; IRD800 E+AA/M+CAA; IRD700 E+TC/M+CAT; IRD800 E+AA/M+CAT;IRD700 E+GG/ $\mathrm{M}+\mathrm{CAA}$; and IRD800 E+CC/M+CAA) that showed clear scorable and also highly polymorphic bands (Table 2) were selected for fluorescent-AFLP reactions with the samples of the 42 Dieffenbachia and five other aroid cultivars listed in Table 1.

DATA ANALYSIS. For the genetic similarity analysis, AFLPbands were visually scored as present (1) or absent (0) to create the binary data set. The data was entered into a binary data matrix as discrete variables. Jaccard's coefficient of similarity (Sneath and Sokal, 1973) was calculated for all pair-wise comparisons among the 42 Dieffenbachia cultivars and 5 other aroid genera as follows: Jaccard $=\mathrm{N}_{\mathrm{AB}} /\left(\mathrm{N}_{\mathrm{AB}}+\mathrm{N}_{\mathrm{A}}+\mathrm{N}_{\mathrm{B}}\right)$, where $\mathrm{N}_{\mathrm{AB}}$ is the number of bands shared by two cultivars (A and B), $N_{A}$ represents amplified fragments in cultivar $A$ and $N_{B}$ represents fragments in cultivar $B$. A dendrogram was generated by cluster analysis using the unweighted pair group method of the arithmetic averages (UPGMA). Principal coordinated analysis (PCOA) was also carried out to show multiple dimension of the distribution of the cultivars in a scatter-pot (NTSYS-pc, version 2.1) (Rohlf, 2000).

\section{Results and Discussion}

AFLP PROFILES AND ANALYSIS. The six primer sets generated clear-cut AFLP profiles for the 42 Dieffenbachia cultivars and five other aroid cultivars. The duplicated control D. maculata 'Compacta' showed identical AFLP patterns with each primer set used. Examples of the AFLP profiles are shown in Fig. 1. The AFLP fragments generated by the primer sets ranged from 50 to $600 \mathrm{bp}$, with most of them being distributed between 100 and 500 bp. In total, 453 bands were scored, of which 323 (71\%) were polymorphic (Table 2 ). Thus, each primer set generated an average of 75.5 bands with 53.8 being polymorphic. The resolution of the AFLP in this study is comparable to that in other reports of ornamental plants. Debener et al. (2000) reported 66\% to $79 \%$ of polymorphic fragments in sports of rose varieties. Escaravage et al. (1998) found 68\% polymorphic bands in Rhododendronferrugineum L. clones. Tomkins et al. (2001) realized that the average percentage of polymorphism was $79 \%$ per primer combination in daylily (Hemerocallis spp).

GENETIC RELATEDNESS AMONG CULTIVARS. Based on the UPGMA analysis, a dendrogram for the Dieffenbachia cultivars and five other aroid cultivars was constructed (Fig. 2). Forty-two cultivars were divided into three clusters. Cluster I and II comprise 18 and 23 cultivars, respectively. Cluster III has only one cultivar.

Cluster I can be divided into two subclusters: IA and IB. IA contains 'Jungle Giant' and 'Tropic Honey' only. 'Jungle Giant' has solid-green leaves and is probably the largest Dieffenbachia in cultivation. Its canopy height can grow beyond $3.0 \mathrm{~m}$, and leaf size can be $60 \mathrm{~cm}$ long and $25 \mathrm{~cm}$ wide. There is no recorded information about its origin, but it may be collected from the wild as indicated by the name and related to D. maculata as it shares 


\section{IRD700 E+GG/M+CAA}

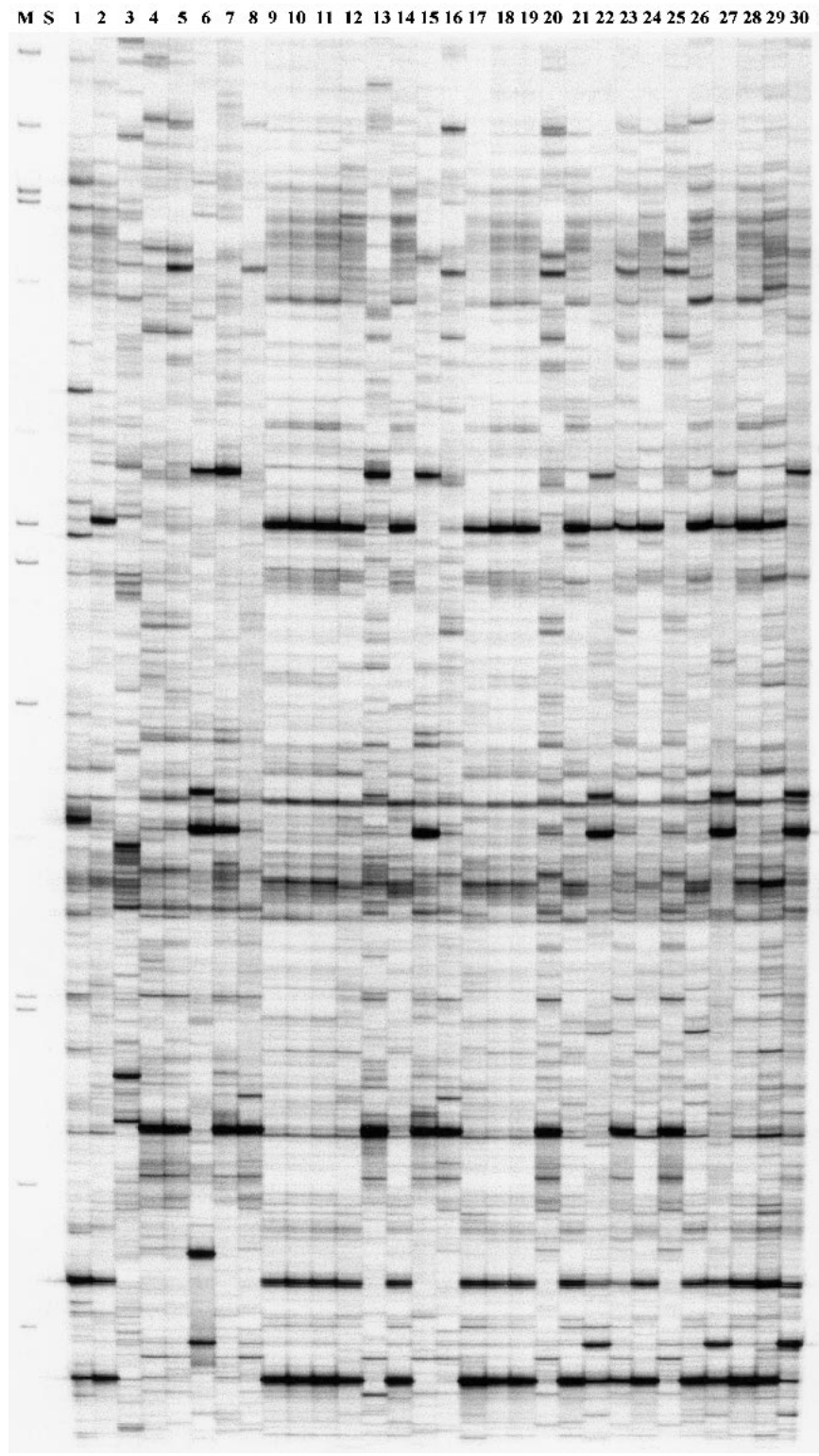

Fig. 1. Fluorescent-AFLP profiles of 30 Dieffenbachia cultivars, a duplicated $D$. maculata 'Compacta', and five other ariod controls using primer IRD700 E+GG/ $\mathrm{M}+\mathrm{CAA}$. The samples are arranged from left to the right in the order of $(\mathrm{M})$ size markers, (S) space, (1) 'Jungle Giant', (2) 'Tropic Honey', (3) D. Leopoldii, (4) 'Bausei', (5) 'Corsii', (6) 'Stenophylla', (7) 'Tropic Alix', (8) 'Camille', (9) ‘Camouflage', (10) ‘Carina', (11) ‘Compacta', (12) 'GoldRush', (13) ‘Gold Dust', (14) 'Honey Dew', (15) 'Octopus', (16) ‘Panther', (17) ‘Parachute', (18) 'Rebecca', (19) 'Sarah', (20) 'Snowflake', (21) 'Sparkles', (22) 'Star Bright', (23) 'Star White', (24) 'Sterling', (25) 'Tiki', (26) 'Triumph', (27) 'Tropic Breeze', (28) 'Exotic Perfection', (29) ‘Tropic Marianne', (30) 'Tropic Rain', (S) space, (31) Anthurium X 'Red Hot', (32) Spathiphyllum X '64760', (33) Philodendron x 'Moonlight', (34) Dieffenbachia maculata 'Compacta', (35) Alocasia X 'Amazonica', (36) Aglaonema commutatum 'Treubii', (S) space, and $(\mathrm{M})$ size markers.

a Jaccard's similarity coefficient of 0.74 with 'Tropic Honey'. 'Tropic Honey' is a hybrid developed from a cross of 'Victory' and 'Tropic Marianne'. Both parents are hybrids and related to D. maculata.

Subcluster IB comprises 15 cultivars. Jaccard's similarity coefficients among these cultivars are 0.73 or higher except for 'Honey Dew'. 'Camouflage', according to the U.S. plant patent No. 12,275 (or PP 12,275), is a somaclonal variant selected from
'Panther'. 'Carina' is a variant isolated from D. maculata 'Camille'. 'Compacta' is a com565 bp mon cultivar of D. maculata (Bown, 2000). 'GoldRush' is the second hybrid selected from $530 \mathrm{bp}$ the cross of 'Victory' and 'Tropic Marianne'. Both 'Rebecca' (PP 6,292) and 'Sarah' are 500 bp somaclonal variants selected from 'Camille'. 'Exotic Perfection' is a cultivar of D. maculata 460 bp (Bown, 2000; Henley, 1992). 'Parachute' is a sport derived from 'Paradise' (Henley, 1992). 'Sparkle' is a hybrid selected from crosses with 20 parents including 'Wilson Delight', 'Perfection', and 'Perfection Compacta', all belonging to D. maculata (Henny, 1995a). 'Sterling' is the third hybrid selected from the 364 bp cross 'Victory' and 'Tropic Marianne' (Henny 350 bp et al., 2003). 'Tropic Marianne'(PP 8,832) is a hybrid selected from a cross of an unidentified species (Missouri Botanic Garden accession No. MGB-737081) with an unnamed hybrid $300 \mathrm{bp}$ that was derived from a cross of 'Marianne' and D. hoffmanii. There is no botanical standing for D. hoffmanii (Bailey and Bailey, 1976); according to Huxley (1998), it may actually 255 bp be D. maculata 'Hoffmanii'.

'Trumph' is a hybrid selected from four crosses of seven different parents including D. hoffmanii, 'Camille', and 'Wilson Delight' 204 bp (Henny et al., 1987a). 'Paradise' (PP 6,854)

200 bp was selected from a cross of $D$. maculata 'Marianne' and 'Wilson Delight'. 'Bali Hai' (PP 6,872) was developed from a cross of $D$. rex and an unnamed D. rex hybrid. However, botanical standing for $D$. rex has not been confirmed. The close similarity of 'Bali Hai' with the 'Paradise' (0.92) may indicate that D. rex is close to D. maculata as well. 'Victory' is a hybrid selected from two crosses involving three parents: 'Wilson Delight', 'Perfection', and 'AREC V-78' (Henny et al., 1987b). 'Honey Dew' is a sport selected from 'Camille' (Henley, 1992).

Cultivars in cluster II are more diverse than those in cluster I as Jaccard's similarity coefficients range from 0.42 to 0.86 compared to 0.59 to 0.98 in cluster I (Fig. 2). There are also two subclusters in cluster II. Subcluster IIA contains 14 cultivars, and subcluster IIB comprises nine cultivars. 'Bausei' is $D$. x Bausei, probably the oldest hybrid, developed from a cross between $D$. maculata and D. weirii in 1870 (Birdsey, 1951). 'Corsii' or D. x Memoria-Corsii, is a hybrid selected from a cross of D. maculata and D. wallisii (Bailey and Bailey, 1976). 'BT-1' is a tetraploid 'Bausei', and 'MCT-1' is a tetraploid 'Corsii'. The fact that two diploid hybrids $(2 n=34)$, 'Bausei' and 'Corsii', are closer than their respective tetraploid types, 'BT-1' and 'MCT-1' (Fig. 2), raises a concern that 'Corsii' may actually be a hybrid developed from a cross of $D$. maculata with $D$. weirii rather than with $D$. wallisii. Otherwise, 'Bausei' should be close to 'BT-1' and 'Corsii' close to 'MCT-1'.

The background of 'Panther' is unknown. 'Snowflake' is a sport of 'Tiki', and 'Tiki' (PP 7,298) is a sport selected from $D$. x Memoria-Corsii. 'Star White' is a hybrid (Henny et al., 1992) resulting from five crosses with nine different parents including 
'Wilson Delight', 'Camille', and 'Hoffmannii'. 'Camille' is a sport of 'Perfection' (Huxley, 1998). 'Tropic Alix' is a sport of D. maculata 'Tropic Snow' (Henley, 1992). The origin of 'Gold Dust' is unknown. 'JT-1' is a tetraploid 'Jenmannii'. Dieffenbachia maculata var. angustior subvar. jenmannii is another old cultivar, discovered by G.S. Jenman, the superintendent of the Botanical Garden in Georgetown, Guyana, in the 1840 (Birdsey, 1951). The background of 'Octopus' is unknown.
There are nine cultivars in the subcluster IIB. 'Stenophylla' is a very narrow leafed plant with unknown species information, but its flowering habit closely resembles 'Angustior Angustifolia'. 'Angustior Angustifolia' is D. maculata var. angustior angustifolia, native to Guyana. ' 72801 ' is selected from progenies of selfed 'Angustior Lancifolia'. 'Angustior Lancifolia' is D. maculata var. Angustior Lancifolia, also native to Guyana. 'Star Bright' is a hybrid selected from crosses of several parents, which include

Table 1. List of 42 Dieffenbachia cultivars and five other ariod cultivars used in this study.

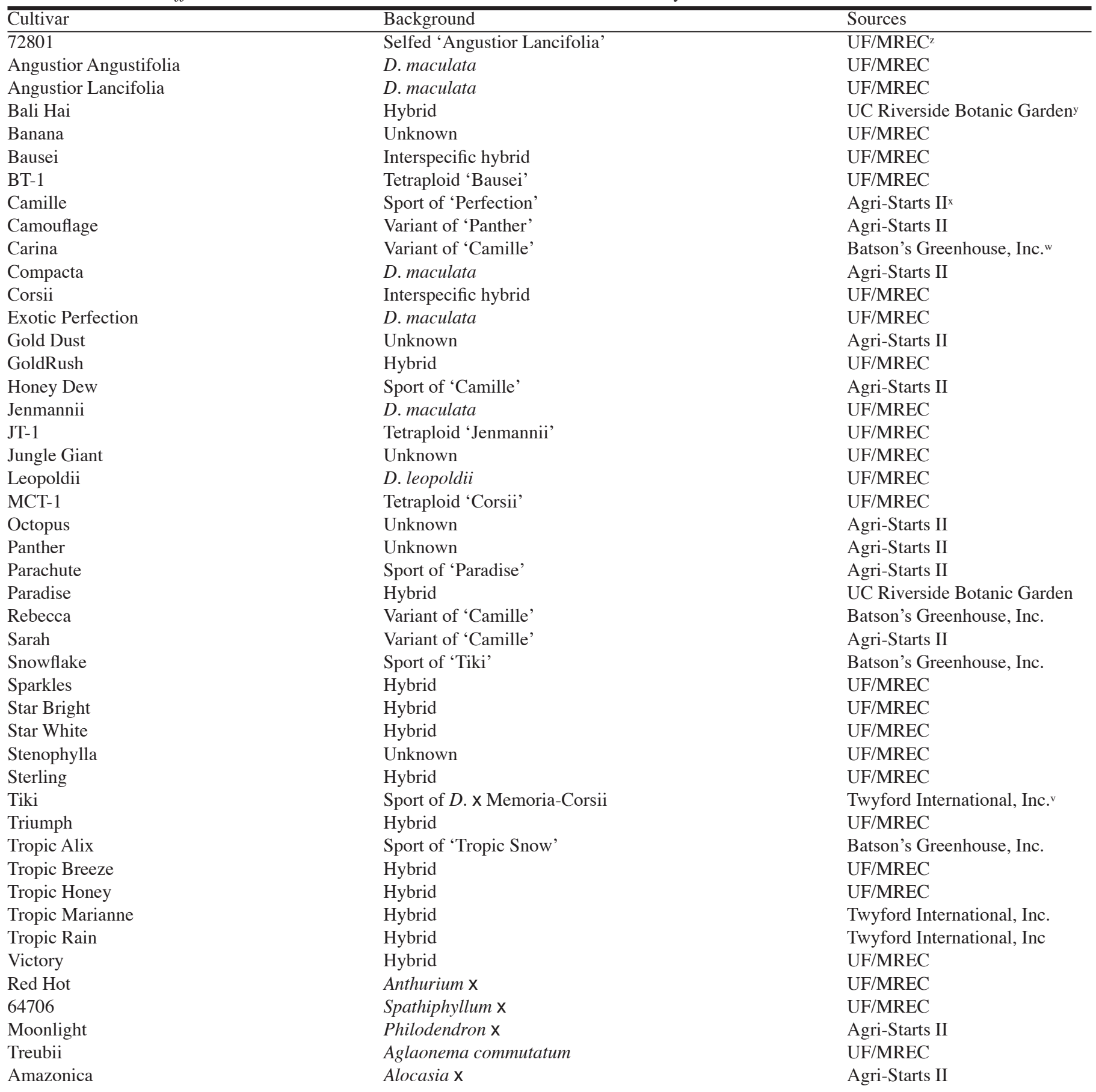

zUniversity of Florida, Mid-Florida Research and Education Center, Apopka, Fla.

yUniversity of California Riverside Botanic Garden, Riverside, Calif.

xAgri-Starts-II, Inc., Apopka, Fla.

wBatson's Greenhouse, Inc., Mt Dora, Fla.

vTwyford International, Inc., Apopka, Fla. 


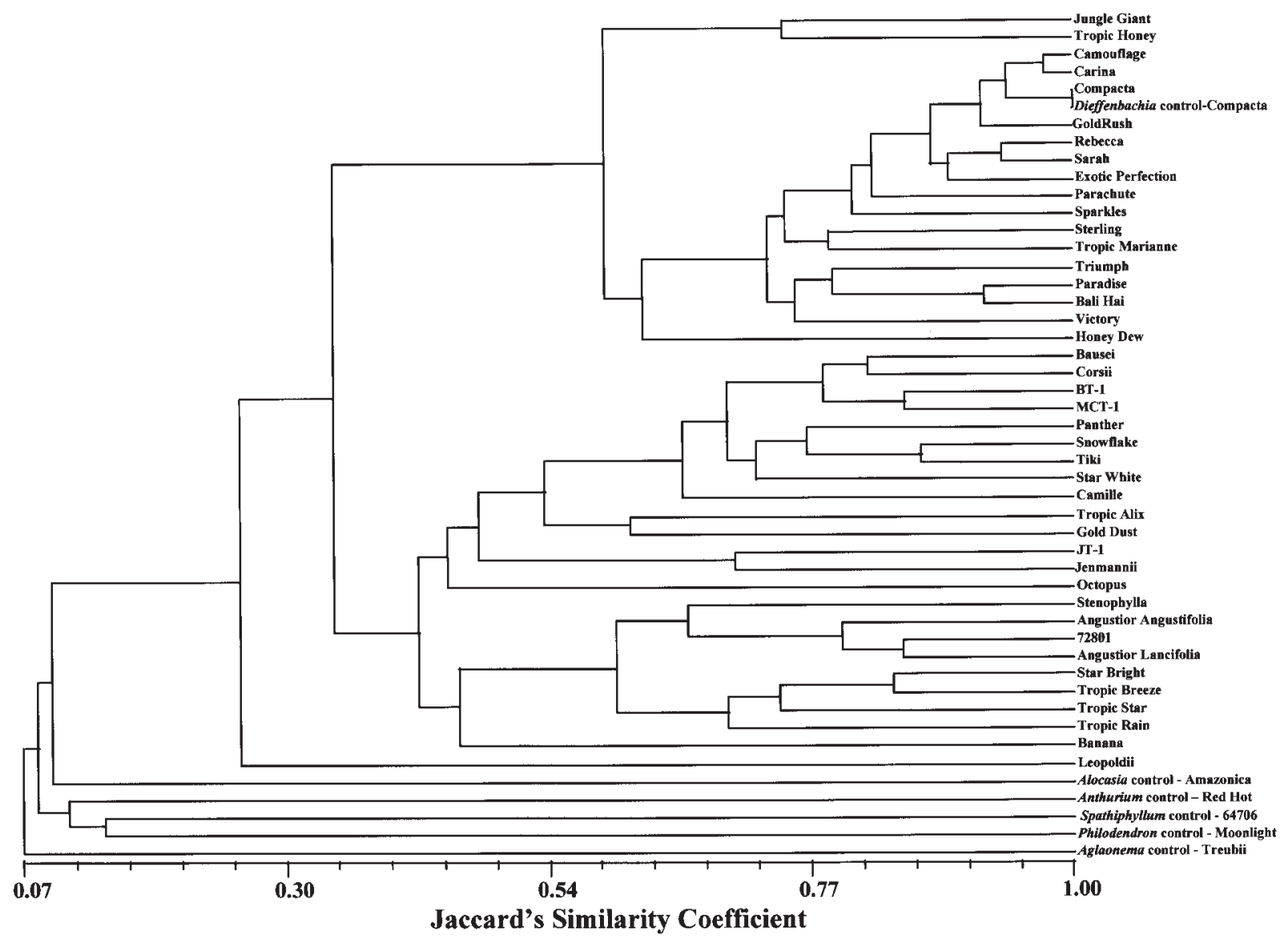

Fig. 2. Dendrogram of 42 Dieffenbachia cultivars and five other aroid genera resulting from a UPGMA cluster analysis based on Jaccard's similarity coefficients obtained from 453 polymorphic AFLP markers.

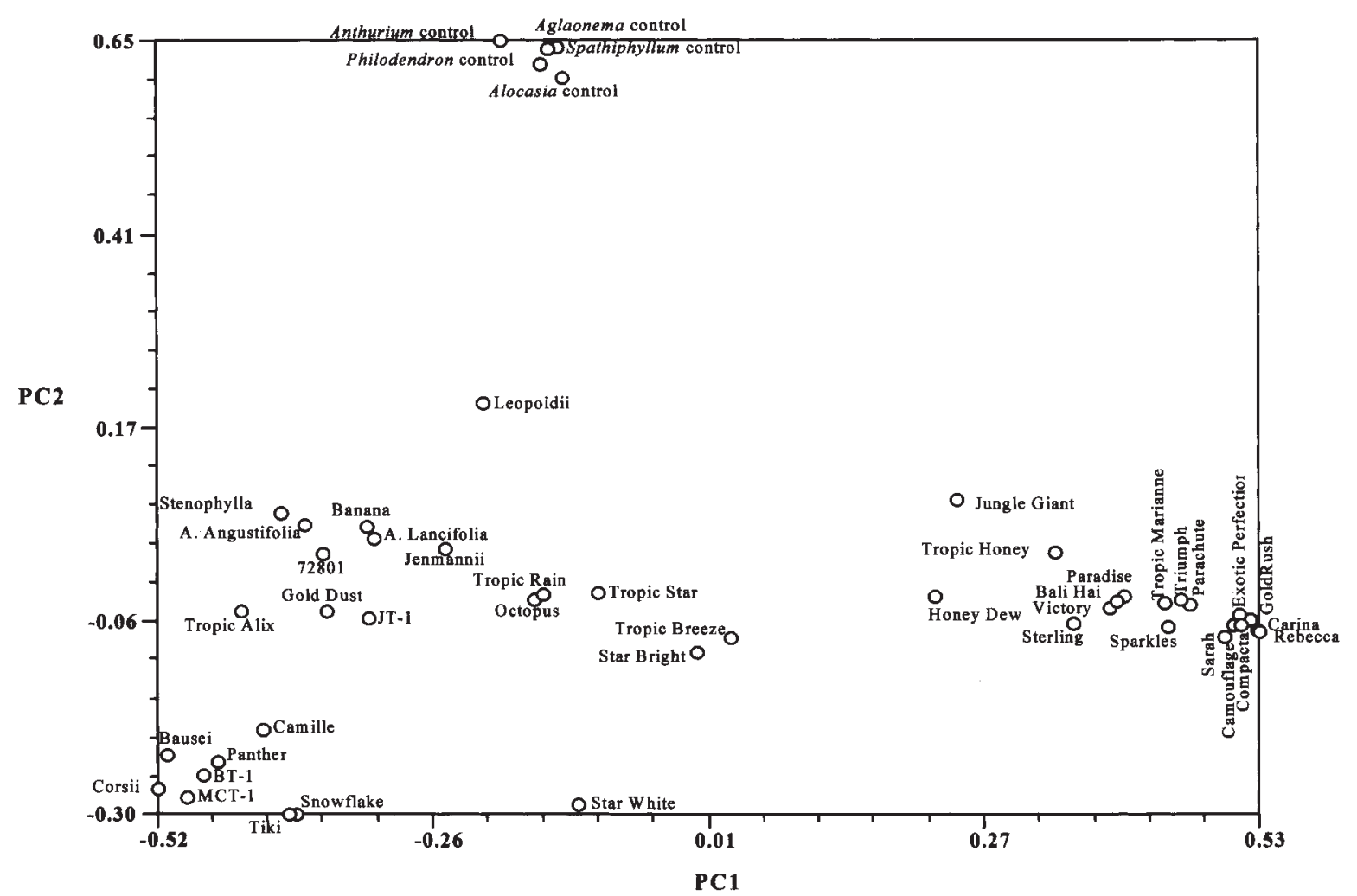

Fig. 3. Principal coordinate analysis plot of 42 Dieffenbachia cultivars and five other aroid genera for the first and second principal coordinates estimates based on 453 AFLP markers derived from six primer sets using Jaccard's similarity matrix. 
'Angustior Lancifolia'(Henny, 1995b). ‘Tropic Breeze' is a hybrid selected from a cross between D. fourneri and 'Angustior Lancifolia'. 'Tropic Star' is a hybrid selected from a cross of 'Perfection' and 'Angustior Lancifolia' (Henny et al., 1988). 'Tropic Rain' is a hybrid developed from cross between $D$. daguensis and $D$. amoena. 'Banana' is morphologically similar to 'Jungle Giant' as it also a large-sized green leaf plant. Genetically, however, they are distantly related, as their Jaccard's similarity coefficient is only 0.35 . Distinct differences between the two are that 'Banana' has narrower leaves and can continue flowering.

There is only one cultivar in cluster III, which is D. leopoldii Bull. It has broadly elliptic to ovate leaves with a stunning white midrib that appears to almost glow. Dieffenbachia leopoldii is native to Costa Rica (Bailey and Bailey, 1976). The Jaccard's similarity coefficient between $D$. leopoldii and the rest of the cultivars is only 0.25 , suggesting that it is rather distantly related to the other cultivars.

The PCOA was used to visualize the genetic relationships among cultivars. The PCOA separations generated three groups of cultivars that support the results of three clusters obtained with the cluster analysis (Fig. 3). The scattered position of cultivars in cluster II suggests that these cultivars are genetically more diverse than those in the cluster I.

We included one cultivar each of five other genera of Araceae (Alocasia, Anthurium, Aglaonema, Philodendron, and Spathiphyllum) as controls in this study. The five controls were properly positioned outside the Dieffenbachia clusters. The Jaccard's similarity coefficients among the five genera are $<0.14$, and their similarity with Dieffenbachia cultivars is $<0.1$.

AFLP MARKERS AND FUTURE Dieffenbachia BREEDING. Results from this study prove the sensitivity of AFLP analysis in discrimination of cultivars. This is particularly true for those cultivars resulting from the crosses of the same cultivars or the same cultivar with different ploidy levels. For example, 'Tropic Honey', 'GoldRush', and 'Sterling' are clearly distinguished even though they selected from the cross of 'Victory' and 'Tropic Marianne'. 'BT-1' and 'MCT-1', tetraploid types of 'Bausei' and 'Corsii', respectively, were also differentiated by AFLP markers. We are also able to identify 17 unique bands for 'Leopoldii', one each for 'Compacta', 'Stenophylla', and 'Tropic Breeze', two each for 'Banana' and 'Panther', and three each for 'Gold Dust', 'Jungle Giant', 'JT-1', and 'Tropic Alix'. These unique bands would be important markers for identification and protection of the cultivars.

As indicated by Ellis et al. (1997), AFLP markers allow a retrospective analysis of breeding and selection consequences on new cultivar production. This investigation has shown that the cultivar origins inferred from the AFLP markers coincide with those of published results and our records. Most importantly, this study provides genetic similarity data as to how closely these cultivars are related. In general, increasing the genetic variability in the Dieffenbachia gene pool is needed, but the genetic similarity of many cultivars is not as close as previously thought. Jaccard's similarity coefficients for cultivars in cluster I are higher than those in cluster II. This close similarity could be explained by the fact that the 18 cultivars, except 'Jungle Giant', in the cluster I are exclusively related to D. maculata and some of them are sports or variants. While concerning about the genetic diversity, attention should be particularly paid to 'Camouflage', 'Carina', 'Compacta', 'GoldRush', 'Rebecca', 'Sarah', and 'Exotic Perfection' as these cultivars are currently most common in production, but their Jaccard's similarity coefficients are 0.87 or higher.
Although a threshold for the similarity is arbitrary depending on the number of primer sets used and markers produced as well as pedigree information (Carr et al., 2003; Le Clerc et al., 2002), we believe that a Jaccard's similarity coefficient of 0.87 could indicate a rather narrow genetic base. In contrast, the reasons for more diverse cultivars in cluster II could be explained by the fact that many hybrids were developed from $D$. maculata crossed with either cultivars of other species, such as D. weirii, D. fourneri, and $D$. daguensis, or some geographically distant $D$. maculata, such as 'Angustior Angustifolia' and 'Angustior Lancifolia'. Thus, it appears that interspecific hybridization or crossing with geographically distant cultivars could be solutions to broaden genetic diversity among cultivated Dieffenbachia.

This study also suggests that different Dieffenbachia cultivars can be selected from the same cross since, if using highly heterozygous hybrid parents, the $\mathrm{F}_{1}$ is actually a segregating generation allowing selection of desirable individuals that can be increased by tissue culture. For example, 'Tropic Honey', 'GoldRush', and 'Sterling' were selected from the cross of 'Victory' and 'Tropic Marianne'. 'Tropic Honey' has showy yellow-green leaves highlighted by a dark green margin; 'GoldRush' has yellow-green leaves and a white midvein; whereas 'Sterling' shows dark green leaves with a white midvein. In addition to their morphological differences, these three cultivars well separated in the dendrogram (Fig. 2).

Additionally, some distant relationships exist between sports and their parents. We included 10 sports or somaclonal variants in this study. Some sports were close to their parental cultivars. For example, 'Snowflake' is next to 'Tiki', and 'Tiki' is relatively close to 'Corsii'. Whereas, other sports are distant from their parental cultivars. 'Camouflage' is distant from 'Panther' by a Jaccard's similarity coefficient of 0.35 . 'Carina', 'Rebecca', and 'Sarah' are variants of and 'Honey Dew' is sport of 'Camille'; these mutants were also distant from 'Camille' by a Jaccard's similarity coefficient of 0.35 . One explanation for the distant relationships is the increased accumulation of somatic mutations in certain cultivars. As Dieffenbachia cultivars are currently increased by tissue culture, in addition to the existing somatic mutations that give rise to some new cultivars, additional mutations could occur during continued tissue-culture propagation to further enhance genetic dissimilarities. Since the majority of polymorphic AFLP fragments are considered as the result from base substitutions within the restriction sites or within the nucleotides (Kuiper et al., 1998), increased accumulation of mutations could be revealed by increased polymorphism at DNA levels. Another possible explanation is that hypervariable regions might exist in some Dieffenbachia cultivars. Mutations derived from tissue culture that affect the same regions of rye and rice genomes have been reported (Linacero and Vazquez, 1992; Xie et al., 1995), and the region subjected to the high mutation is called the hypervariable region (Linacero et al., 2000). It is also possible that addition or deletion of chromosomes may be implicated in the variation even through all these variants or sports theoretically should have the chromosome number of $2 n=34$. Future studies are warranted to determine such possible sources of variation in these cultivars including cytological examination of their chromosome numbers.

To our knowledge, this is the first molecular fingerprint study of the genetic relationships of Dieffenbachia cultivars. We were able to distinguish 42 cultivars based on polymorphisms generated by six primer sets. The AFLP profiles and the clusters we identified can be used as a basis for comparison of other Dieffenbachia 
species or cultivars. The genetic similarity among cultivars established could help future Dieffenbachia germplasm identification, preservation, and new cultivar development.

\section{Literature Cited}

Bailey, L.H. and E.Z. Bailey. 1976. Hortus III. Macmillon, New York. Barcaccia, G., E. Albertini, and M. Falcinelli. 1999. AFLP fingerprinting in Pelargonium peltatum: Its development and potential in cultivar identification. J. Hort. Sci. Biotechnol. 74: 243-250.

Birdsey, M.R. 1951. The cultivated aroids. Gillick Press, Berkeley, Calif.

Bown, D. 2000. Aroids: Plants of the arum family. $2^{\text {nd }}$ ed. Timber Press, Portland, Ore.

Carr, J., M. Xu, J.W. Dudley, and S.S. Korban. 2003. AFLP analysis of genetic variability in New Guinea impatiens. Thero. Appl. Genet. 106:1509-1516.

Chen, J., R.J. Henny, and D.B. McConnell. 2002. Development of new foliage plant cultivars, p. 466-472. In: J. Janick and A. Whipkey (eds.). Trends in new crops and new uses. ASHS Press, Alex., Va.

Debener, T, T. Janakiram, and L. Mattiesch. 2000. Sports and seedlings of rose varieties analyzed with molecular markers. Plant Breeding 119:71-74.

Ellis, R.P., J.W. McNicol, E. Baird, A. Booth, and P. Lawrence. 1997. The use of AFLPs to examine genetic relatedness in barley. Mol. Breeding 3:359-369.

Escaravage, N., S. Questiau, A. Pornon, B. Doche, and P. Taberlet. 1998. Clonal diversity in a Rhododendron ferrugineum $\mathrm{L}$. (Ericaceae) population inferred from AFLP makers. Mol. Ecol. 7:975-982.

FNGA (Florida Nurserymen and Growers Association) Locator 1992 1993, 2002-2003. Orlando, Fla.

Griffith, L.P. 1998. Tropical foliage plants: A grower's guide. Ball Publ. Batavia, Ill.

Henley, R.W. 1992. Dieffenbachia to know and grow. Proc. Fla. State Hort. Soc. 105:256-262.

Henny, R.J. 1977. Breeding, growing and observing Dieffenbachia species and seedlings. Proc. Fla. State Hort. Soc. 90:94-96.

Henny, R.J. 1995a. 'Sparkles' Dieffenbachia. HortScience 30:163.

Henny, R.J. 1995b. 'Star Bright' Dieffenbachia. HortScience 30:164.

Henny, R.J. and J. Chen. 2003. Foliage plant cultivar development. Plant Breeding Rev. 23:245-290.

Henny, R.J., J. Chen, and D.J. Norman. 2003. 'Sterling' Dieffenbachia. HortScience (in press).

Henny, R.J., C.A. Conover, and R.T. Poole. 1987a. 'Triumph' Dieffenbachia. HortScience 22:965-966.

Henny, R.J., C.A. Conover, and R.T. Poole. 1987b. 'Victory' Dieffenbachia. HortScience 22:967-968.

Henny, R.J., R.T. Poole, and C.A. Conover. 1988. 'Tropic Star' Dieffenbachia. HortScience 23:919-920.

Henny, R.J., R.T. Poole, and C.A. Conover. 1992. 'Star White' Dieffenbachia. HortScience 27:82-83.
Huxley, A. 1998. The new royal horticultural society dictionary of gardening. Macmillon, London.

Jones, G.E. 1957. Chromosome numbers and phylogenetic relationship in the Araceae. PhD diss., Univ. Va., Charlottesville.

Kuiper, M.T.R. 1998. Building a high-density genetic map using the AFLPTM technology, p. 157-171. In. J.M. Martnez-Zapater and J. Salinas (eds.). Arabidopsis protocols: methods in molecular biology. vol. 82. Human Press, Totowa, N.J.

Le Clerc, V., M. Briard, and P. Revollon. Influence of number and map distribution of AFLP markers on similarity estimates in carrot. Theor. Appl. Genet. 106:157-162.

Linacero, R., E.F. Alves, and A.M. Vazquez. 2000. Hot spots of DNA instability revealed through the study of somaclonal variation in rye. Theor. Appl. Genet. 100:506-511.

Linacero, R. and A.M. Vazquez. 1992. Genetic analysis of chlorophylldeficient somaclonal variants in rye. Genome 35:981-984.

Loh, J.P., R. Kiew, A. Kee, L.H. Gan, and Y.Y. Gan. 1999. Amplified fragment length polymorphism (AFLP) provides molecular markers for the identification of Caladium bicolor cultivars. Ann. Bot. 84: $155-161$

Loh, J.P., R. Kiew, A. Hay, A. Kee, L.H. Gan, and Y.Y. Gan. 2000. Intergeneric and interspecific relationships in Araceae tribe Caladieae and development of molecular markers using amplified fragment length polymorphism (AFLP). Ann. Bot. 85:371-378.

Mayo, S.J., J. Bogner, and P.C. Boyce. 1997. The genera of Araceae. Royal Bot. Gardens, Kew.

Myburg, A.A., D. O'Malley, R.R. Sederoff, and R. Whetten. 2000. High-throughput multiplexed AFLP analysis of interspecific hybrids of Eucalyptus trees species, p. 544. In: Plant and animal genome VIII conference, San Diego, Calif.

Prabhu, R.R. and P.M. Gresshoff. 1994. Inheritance of polymorphic markers generated by DNA amplification fingerprinting and their use as genetic markers in soybean. Plant Mol. Biol. 26:105-116.

Qamaruz-Zaman, F., M.F. Fay, J.S. Parker, and M.W. Chase. 1998. The use of AFLP fingerprinting in conversation genetics: A case study of Orchis simia (Orchidaceae). Lindleyana 13:125-133.

Rohlf, F.J. 2000. NTSYSpc, Numerical taxonomy and multivariate analysis system, version 2.1 user guide. Exeter Software Publ. Setauket, N.Y.

Sneath, P.H.A. and R.R. Sokal. 1973. Numerical taxonomy: the principles and practice of numerical classification. W.H. Freeman, San Francisco, Calif.

Tomkins, J.P., T.C. Wood, L.S. Barnes, A. Westman, and R.A. Wing. 2001. Evaluation of genetic variation in the daylily (Hemerocallis spp.) using AFLP markers. Theor. Appl. Genet. 102:489-496.

Vos, P., R. Hogers, M. Bleeker, M. Reijans, T. van de Lee, M. Hornes, A. Frijters, J. Pot, J. Peleman, M. Kupier, and M. Zabeau. 1995. AFLP: A new technique for DNA fingerprinting. Nucleic Acids Res. 23:4407-4414.

Xie, Q.J., J.H. Oard, and M.C. Rush. 1995. Genetic analysis of a purple-red hull rice mutation derived from tissue culture. J. Hered. 86:154-156. 